\title{
Absence of albuminuria in type 2 diabetics with classical diabetic nephropathy: Clinical pathological study
}

\author{
Pooja Budhiraja $^{1,2}$, Bijin Thajudeen ${ }^{1,2}$, Mordecai Popovtzer ${ }^{1,2}$ \\ ${ }^{1}$ Department of Medicine, Southern Arizona Veterans Affairs Health Care System, Tucson, USA \\ ${ }^{2}$ Department of Medicine, University of Arizona College of Medicine, Tucson, USA \\ Email: budhirajap@yahoo.com
}

Received 13 March 2013; revised 13 April 2013; accepted 13 May 2013

Copyright (c) 2013 Pooja Budhiraja et al. This is an open access article distributed under the Creative Commons Attribution License, which permits unrestricted use, distribution, and reproduction in any medium, provided the original work is properly cited.

\begin{abstract}
Background: Diabetic nephropathy is the most common cause of chronic kidney disease and the number afflicted patients continues to rise. The presence of proteinuria has been considered as a prerequisite for the diagnosis of diabetic nephropathy. But one third to one half of type 2 diabetics with CKD have no proteinuria and the pathology of non proteinuric CKD in this group remains unclear as renal biopsy is commonly not performed in these patients. The present study addresses the question: Can a classical diabetic nephropathy occur in the absence of proteinuria? Method: We examined renal biopsies of subjects who underwent nephrectomy from 1999 to 2009 for renal cancer, had eGFR $<60 \mathrm{ml} / \mathrm{min}$ and no microalbuminuria or proteinuria. 10 diabetics were matched with 10 non diabetics for age, hypertension and baseline creatinine. Results: The diabetic subjects had advanced diabetic lesions even in absence of proteinuria. Tubules and tubular-interstitium was relatively well preserved. Diabetic glomerulosclerosis can occur in the absence of microalbuminuria. Conclusions: It is becoming increasingly apparent that a considerable proportion of subjects with type 2 diabetes can develop renal impairment in the absence of albuminuria. Diabetic glomerulosclerosis may develop before the proteinuria can be detected and relying on albumin excretion as first sign for renal involvement may be too late in diagnosing and modifying the progression of the kidney disease.
\end{abstract}

Keywords: Kimmelstiel-Wilson Lesions; Diabetes Mellitus; Nephropathy; Albuminuria

\footnotetext{
${ }^{2 h^{*}}$ The authors of this manuscript report no conflict of interest.
}

\section{INTRODUCTION}

\subsection{Background}

Diabetic nephropathy is the most common cause of chronic kidney disease in the Unites states and the number of affected patients continues to rise. According to the classical view, type 2 diabetic nephropathy is typically presented with Kimmelstiel-Wilson lesions of the glomerulus, as shown by the renal biopsies, and its classical clinical course is characterized by the progression from microalbuminuria to proteinuria accompanied by renal dysfunction, and finally, end-stage renal disease [1-4]. Persistent albuminuria has been considered to be the hallmark for diabetic nephropathy and is believed to be the earliest marker of glomerular diseases.

However, it has been now established that a nonalbuminuric or nonproteinuric type of kidney disease is also quite prevalent in type 2 diabetics. Around one third to half of type 2 diabetics may have CKD without proteinuria $[5,6]$. CKD in absence of proteinuria has been postulated to be due to atubular glomeruli, renal microvascular atherosclerotic disease, analgesics etc. [7,8]. Renal insufficiency in type 2 diabetics with normoalbuminuria is sometimes labeled as non diabetic kidney disease and biopsy is usually not performed.

Caramori et al. reported presence of diabetic glomerulosclerosis on the renal biopsy in 23 patients with type 1 diabetes who had CKD and normoalbuminuria [9]. Yagil et al. examined the pathology of kidney failure in the Cohen diabetic rat which is an experimental model suggestive of human type 2 diabetes. In the study Cohen diabetic sensitive (CDs) and Cohen diabetic resistant (CDr) rats were fed regular diet or a diabetogenic diet. CDs rats that were fed diabetogenic diet developed diabetes, renal insufficiency and nonproliferative diabetic retinopathy but urinary protein excretion was normal. 
Histological examination of the renal tissue of CDs revealed increase in mesangial matrix, thickening of glomerular capillary wall, thickening of basement membrane and increased type IV collagen in glomeruli and interstitium of CDs [10].

\subsection{Objectives}

Except for type 1 diabetes, studies showing renal histological changes in patients with type 2 diabetes, normoalbuminuria and renal insufficiency have not been performed. The aim of this current study was to address the question: Can a classical diabetic nephropathy with declining kidney disease, occur in the absence of proteinuria and/or absence of microalbuminuria in type 2 diabetics. We identified a group of normoalbuminuric type 2 diabetic patients with low GFR and compared their clinical and structural parameters to normoalbuminuric patients with similar GFR. We compared biopsies of subjects who underwent nephrectomy for renal cancer, had estimated glomerular filtration rate (eGFR) < $60 \mathrm{ml} / \mathrm{min}$ and were normoalbuminuric.

\section{METHODS}

\subsection{Subjects}

We compared 20 subjects who underwent nephrectomy for Renal cancer between year 1999 to 2009, had eGFR $<60 \mathrm{ml} / \mathrm{min}$, normoalbuminuria and absence of other known glomerulopathies. Biopsies of normoalbuminuric type 2 diabetics $(n=10)$ were compared with nondiabetic controls $(n=10)$.

\subsection{Variables}

Data regarding age, history of hypertension, duration of diabetes, presence of retinopathy or neuropathy at the time of nephrectomy, medication including use of insulin, angiotensin converting enzyme inhibitors (ACEi) or Angiotenin receptor blockers (ARBs) were obtained from the electronic chart. GFR was estimated by Modification of Diet in Renal Disease equation. It uses standardized serum creatinine, age, gender and race to estimate GFR. Serum creatinine within 1 month prior to surgery and one month after the surgery was noted. Urinalysis for total protein was done using automated reading by reagent strip. Normoalbuminuria was defined as Albumin creatinine ratio (ACR) $<30 \mathrm{mg} / \mathrm{g}$ within 6 months before the surgery. Glycosylated hemoglobin (HbA1c) with past 6 months was also recorded.

\subsection{Light Microscopy}

Fifty to hundred glomerulus were examined under light microscopy for each subject. Four classes of glomerular lesions were defined per Renal Pathology Society Classification. Class I: isolated glomerular basement membrane thickening; class IIa: mild mesangial thickening; class IIb: severe mesangial expansion but without nodular sclerosis; class III: at least one glomerulus with nodular increase in mesangial matrix (Kimmelstiel-Wilson); class IV: more than 50\% global glomerulosclerosis due to diabetes [11]. Percentage of interstitial fibrosis and tubular atrophy (IFTA) was also noted. Small vessel was reported as normal if there was absence any noticeable alteration of the vessel wall, mild hyalinosis if vessel wall hyalinosis comprised $25 \%$ of the circumference, moderate if vessel wall hyalinosis was $>25 \%$ and $<50 \%$, severe if the hyalinosis was $>50 \%$.

\subsection{Statistical Methods}

We compared age, presence of hypertension, hypertension medication use, serum creatinine, eGFR between those with and those without diabetes using Student's t-test or Chi-square tests. Statistical significance was defined as 2-tailed p value less than 0.05. We compared the light microscopy findings between the two groups.

\section{RESULTS}

\subsection{Participants}

There were 20 participants who were studied, 10 diabetics and 10 controls. Both groups were similar for age, mean serum creatinine, presence of HTN (Table 1). All subjects were male and Caucasians. Mean age of the diabetic group was $65.6 \pm 7.4$ years, mean eGFR $53 \pm$ $4.9 \mathrm{ml} / \mathrm{min}$. In the diabetic group $40 \%$ were on oral meds for diabetes, $20 \%$ on Insulin and $40 \%$ were diet controlled. Mean HbA1c was $7.2 \pm 2.5$. Serum creatinine pre nephrectomy was $1.4 \pm 0.13 \mathrm{mg} / \mathrm{dl}$ and post nephrectomy $1.6 \pm 0.15 \mathrm{mg} / \mathrm{dl}$. $40 \%$ were not on ACEi/ARBs.

Table 1. Demographic and clinical characteristics of type 2 diabetic and controls who underwent nephrectomy.

\begin{tabular}{|c|c|c|c|}
\hline & Diabetics (10) & Controls (10) & $\mathrm{p}$ value \\
\hline Age & $65.6 \pm 7.4$ & $66.6 \pm 7.9$ & 0.8 \\
\hline Gender & Male & Male & NS \\
\hline HTN & $90 \%$ & $100 \%$ & NS \\
\hline $\begin{array}{l}\text { Pre nephrectomy } \\
\text { eGFR (ml/min) }\end{array}$ & $53 \pm 4.9$ & $51.6 \pm 5.7$ & 0.6 \\
\hline $\begin{array}{l}\text { Pre nephrectomy } \\
\text { Creatinine (mg/dl) }\end{array}$ & $1.4 \pm 0.13$ & $1.4 \pm 0.15$ & 0.9 \\
\hline $\begin{array}{l}\text { Post nephrectomy } \\
\text { Creatinine (mg/dl) }\end{array}$ & $1.6 \pm 0.15$ & $1.7 \pm 0.27$ & 0.2 \\
\hline $\begin{array}{l}\text { Post nephrectomy } \\
\text { GFR (ml/min) }\end{array}$ & $46.6 \pm 5.7$ & $42.8 \pm 7.3$ & 0.2 \\
\hline
\end{tabular}




\subsection{Light Microscopy Findings}

\subsubsection{Diabetics}

Capillary wall thickening was present in all diabetics without proteinuria. Out of 10 diabetics 2 had severe diffuse mesangial thickening (class IIb) but no nodules while 8 had Kimmelstiel-Wilson nodules noted on the biopsy. The diabetic subjects had advanced diabetic lesions even in absence of proteinuria (Figure 1(a)). Tubules and tubule interstitium was relatively well preserved. Afferent and efferent arteriolar hyalinosis was also observed (Table 2).

\subsubsection{Controls}

Capillary wall thickening and mesangial expansion was not present in control subjects (Figure 1(b)). More obsolescent glomeruli with higher percentage of tubularinterstitial atrophy was noted in the biopsy of control subjects. Hypertensive changes were more common (Table 3).

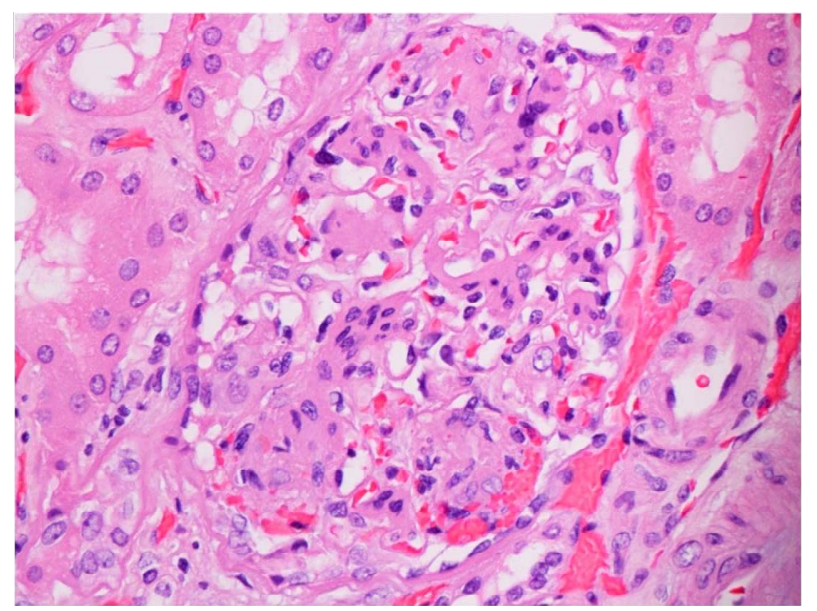

(a)

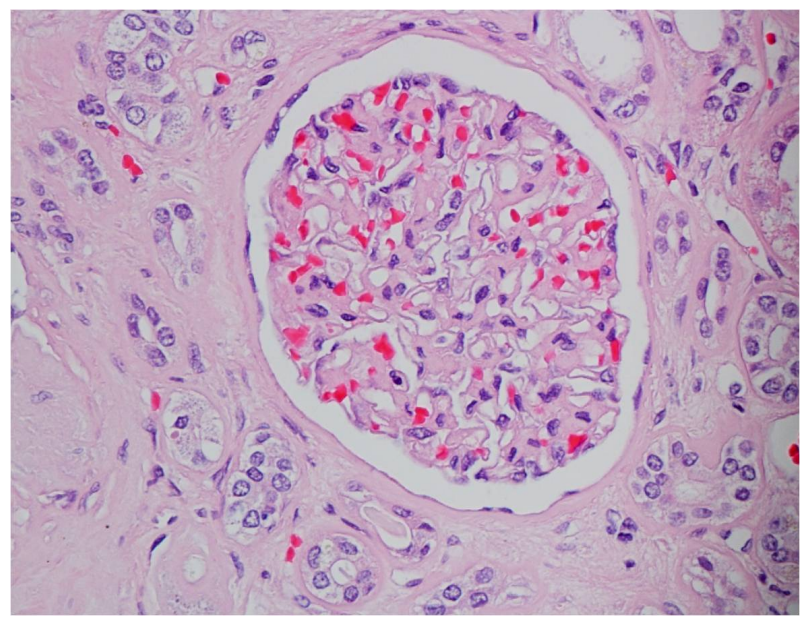

(b)

Figure 1. (a) Light microscopy findings of diabetic subject; (b) Light microscopy findings of control.

\section{DISCUSSION}

It is becoming increasingly apparent that a considerable proportion of subjects with type 2 diabetes can develop renal impairment in the absence of albuminuria $[5,6,12]$. In United Kingdom Prospective Diabetic Study involving 4031 subjects with type 2 diabetes 38\% developed albuminuria and 29\% developed CKD over a median of 15 years of follow up. Among participants who developed CKD, half of them did not have preceeding albuminuria and 39\% did not develop albuminuria during the study [5]. Kramer et al. studied 600 type 2 diabetic patients with normoalbuminuria and found that $13 \%$ had CKD [8]. In another study utilizing third National Health and Nutrition Examination Survey (NHANES) 30\% of the diabetics had renal insufficiency but did not have retinopathy or albuminuria [6]. It was hypothesized that CKD in diabetics without proteinuria could be due to atubular glomeruli, tubular atrophy and interstitial fibrosis rather than classical diabetic glomerulosclerosis [6]. Type 2 diabetes may have considerable decline of renal function while they are still normoalbuminuric [7].

The present study shows diabetic glomeruloslerosis can be present in diabetics with non proteinuric CKD. The above is supported by Cohen rat model in which rats developed diabetes, renal insufficiency and diabetic renal lesions in absence of proteinuria when they were fed diabetogenic diet [10]. Caramori et al. also reported presence of advanced diabetic lesion in type 1 diabetics who had nonproteinurinuric CKD [9]. Absence of proteinuria in presence of advanced glomerular lesion in our study could be due to reabsorption of protein by relatively well preserved tubules in our subjects. The lesions were also noted in subjects whose diabetes was controlled with diet or oral medications. This further raises the question if these lesions can develop in early stages of DM.

The renal lesions of diabetes be early in time than what it has been suspected until now and precede proteinuria. Well preserved tubules may prevent appearance of protein in urine. Early use of RAS blocking agents may be useful in early stages of DM to prevent progression of renal disease.

The study has several limitations. Firstly, it's a small study and the participants were predominantly Caucasian, older than 50 years of age and males. Secondly, some subjects were on RAS blockade agent which may mask the presence of microalbuminuria. Thirdly, we do not have immunoflorescence or electron microscopy data. Recent studies based on high-power electron microscopy have emphasized the role of podocytopathy in the pathogenesis of proteinuria in diabetic kidneys [13-16]. Podocyte detachment from the glomerular basement membrane has been demonstrated in kidney biopsies from type 2 diabetics. Prospective future study should correlate the presence of proteinuria with above changes 
Table 2. Demographic, clinical and histological characteristics of type 2 diabetics.

\begin{tabular}{|c|c|c|c|c|c|c|c|c|c|c|}
\hline Subject number & 1 & 2 & 3 & 4 & 5 & 6 & 7 & 8 & 9 & 10 \\
\hline age & 77 & 66 & 64 & 71 & 60 & 61 & 62 & 78 & 60 & 57 \\
\hline gender & $\mathrm{m}$ & $\mathrm{m}$ & $\mathrm{m}$ & $\mathrm{m}$ & $\mathrm{m}$ & $\mathrm{m}$ & $\mathrm{m}$ & $\mathrm{m}$ & $\mathrm{m}$ & $\mathrm{m}$ \\
\hline DM duration (years) & 4 & 17 & 19 & 1 & $>10$ & NA & 2 & 2 & 1 & 11 \\
\hline DM meds & $\begin{array}{c}\text { Diet } \\
\text { controlled }\end{array}$ & Insulin & Oral & Oral & Insulin & $\begin{array}{c}\text { Diet } \\
\text { controlled }\end{array}$ & $\begin{array}{c}\text { Diet } \\
\text { Controlled }\end{array}$ & $\begin{array}{c}\text { Diet } \\
\text { controlled }\end{array}$ & $\begin{array}{c}\text { Diet } \\
\text { controlled }\end{array}$ & Oral \\
\hline HbA1c & 6.5 & 6.5 & 7 & 7.6 & 12.5 & 6.7 & 6 & 6 & 6 & 6.2 \\
\hline ACEi/ARB & Yes & Yes & Yes & Yes & Yes & Yes & No & No & No & No \\
\hline HTN & Yes & Yes & Yes & Yes & Yes & Yes & Yes & yes & yes & yes \\
\hline Retinopathy & No & NPDR & NPDR & No & No & NA & No & NA & NPDR & No \\
\hline neuropathy & No & Yes & Yes & NA & Yes & Yes & Yes & Yes & NA & Yes \\
\hline $\begin{array}{l}\text { Pre nephrectomy } \\
\text { Creatinine (mg/dl) }\end{array}$ & 1.3 & 1.7 & 1.3 & 1.4 & 1.4 & 1.5 & 1.4 & 1.5 & 1.3 & 1.5 \\
\hline $\begin{array}{c}\text { Pre nephrectomy } \\
\text { eGFR (ml/min) }\end{array}$ & 57 & 43 & 59 & 53 & 55 & 51 & 55 & 48 & 58 & 51 \\
\hline $\begin{array}{l}\text { Post nephrectomy } \\
\text { creatinine (mg/dl) }\end{array}$ & 1.7 & 1.8 & 1.3 & 1.8 & 1.6 & 1.6 & 1.5 & 1.5 & 1.5 & 1.7 \\
\hline $\begin{array}{l}\text { Post nephrectomy } \\
\text { eGFR (ml/min) }\end{array}$ & 42 & 40 & 59 & 40 & 47 & 47 & 50 & 48 & 49 & 44 \\
\hline Capillary wall & Thickened & Thickened & Thickened & Thickened & Thickened & Thickened & Thickened & Thickened & Thickened & Thickened \\
\hline $\begin{array}{l}\text { Tubulointerstitium } \\
\text { atrophy (\%) }\end{array}$ & No & $5 \%$ & No & No & No & $5 \%-10 \%$ & No & $5 \%-10 \%$ & No & No \\
\hline Mesangial changes & III & III & III & IIb & III & III & III & III & III & IIb \\
\hline $\begin{array}{l}\text { Obsolescent } \\
\text { glomeruli (\%) }\end{array}$ & $1 \%$ & $5 \%-10 \%$ & $5 \%$ & $<1 \%$ & $<5 \%$ & $5 \%-10 \%$ & $<1 \%$ & $15 \%$ & $<1 \%$ & $<1 \%$ \\
\hline $\begin{array}{c}\text { Small blood vessel } \\
\text { hyalinosis }\end{array}$ & Mild & Moderate & Mild & Mild & Mild & Mild & Mild & Moderate & Mild & Mild \\
\hline
\end{tabular}

Abbreviations: DM—diabetes mellitus; NA—not available; HbA1c—glycosylated emoglobin; ACEi—angiotensin converting enzyme inhibitors; ARB—angiotensin receptor blockers; eGFR — estimated glomerular filtration rate; NPDR—non proliferative diabetic retinopathy; Mesangial changes—class I: isolated glomerular basement membrane thickening; class IIa: mild mesangial thickening; class IIb: severe mesangial expansion but without nodular sclerosis; class III: at least one glomerulus with nodular increase in mesangial matrix (Kimmelstiel-Wilson); class IV: more than $50 \%$ global glomerulosclerosis due to diabetes.

for elucidation of mechanisms of proteinuria in diabetes [13-16] Finally, the biopsy data was obtained from those who underwent nephrectomy and higher creatinine could be in part due to the involvement of the kidney by tumor. The above and other drawbacks of the present study need to be answered by well designed prospective studies.

In conclusion, to the best of our knowledge, this is the first study evaluating the pathology non proteinuric CKD in type 2 diabetics and comparing the biopsy to age matched controls. Diabetic glomerulosclerosis may occur early in time than what it has been suspected and may precede proteinuria. Relying on albumin excretion as first sign for renal involvement may be too late in diagnosing and modifying the progression of the disease and better markers for monitoring of renal function that can detect early renal damage are much needed. Early use of RAS blocking agents before the detection of microalbuminuria or renal impairment may be beneficial in preserving the renal function in diabetics. Considering the disease burden of diabetes and CKD, these results have important clinical and public health implications. Further prospective studies need to be designed to evaluate the 
Table 3. Demographic, clinical and histological characteristics of controls.

\begin{tabular}{|c|c|c|c|c|c|c|c|c|c|c|}
\hline & 1 & 2 & 3 & 4 & 5 & 6 & 7 & 8 & 9 & 10 \\
\hline Age & 61 & 62 & 66 & 77 & 57 & 68 & 74 & 57 & 79 & 65 \\
\hline ACEi/ARBs & No & Yes & No & No & Yes & Yes & No & No & No & no \\
\hline HTN & Yes & Yes & Yes & Yes & Yes & Yes & Yes & Yes & Yes & No \\
\hline $\begin{array}{l}\text { Pre nephrectomy } \\
\text { creatinine (mg/dl) }\end{array}$ & 1.7 & 1.3 & 1.5 & 1.3 & 1.4 & 1.4 & 1.3 & 1.7 & 1.3 & 1.5 \\
\hline $\begin{array}{l}\text { Pre nephrectomy } \\
\text { eGFR (ml/min) }\end{array}$ & 44 & 59 & 50 & 57 & 56 & 54 & 54 & 42 & 53 & 47 \\
\hline $\begin{array}{l}\text { Post nephrectomy } \\
\text { Creatinine (mg/dl) }\end{array}$ & 2.3 & 1.9 & 1.9 & 1.4 & 1.7 & 1.4 & 1.8 & 1.6 & 1.7 & 1.6 \\
\hline $\begin{array}{l}\text { Post nephrectomy } \\
\text { eGFR (ml/min) }\end{array}$ & 31 & 39 & 40 & 52 & 45 & 56 & 37 & 45 & 39 & 44 \\
\hline Capillary thickness & No & No & No & No & No & No & No & No & No & No \\
\hline $\begin{array}{l}\text { Tubulointerstitium } \\
\text { Atrophy (\%) }\end{array}$ & No & No & No & $10 \%-25 \%$ & $5 \%-10 \%$ & $5 \%-10 \%$ & $5 \%-10 \%$ & $>50 \%$ & $10 \%-25 \%$ & No \\
\hline $\begin{array}{l}\text { Mesangium } \\
\text { thickening }\end{array}$ & No & No & No & No & No & No & No & No & No & No \\
\hline $\begin{array}{c}\text { Obsolescent } \\
\text { glomeruli (\%) }\end{array}$ & $5 \%$ & $<5 \%$ & $<5 \%$ & $20 \%$ & $10 \%$ & $20 \%$ & $10 \%$ & $80 \%$ & $20 \%$ & $<5 \%$ \\
\hline $\begin{array}{l}\text { Small blood vessel } \\
\text { hyalinosis }\end{array}$ & Moderate & Severe & Mild & Moderate & Mild & Moderate & Moderate & Severe & Moderate & Mild \\
\hline
\end{tabular}

Abbreviations: ACEi-angiotensin converting enzyme inhibitors; ARB—angiotensin receptor blockers; eGFR—estimated glomerular filtration rate.

renal histopathology in diabetics with CKD but without proteinuria in diverse populations. In parallel, the effect of early interventions including use of RAS blocking agent, tighter control of diabetes in HbA1c on slowing the progression of the disease needs to be studied.

\section{REFERENCES}

[1] Williams, M.E. (2005) Diabetic nephropathy: The proteinuria hypothesis. American Journal of Nephrology, 25, 77-94. doi:10.1159/000084286

[2] ACE Inhibitors in Diabetic Nephropathy Trialist Group (2001) Should all patients with type 1 diabetes mellitus and microalbuminuria receive angiotensin converting enzyme inhibitors? A meta-analysis of individual patient data. Annals of Internal Medicine, 134, 370-379. doi:10.7326/0003-4819-134-5-200103060-00009

[3] American Diabetes Association Clinical Practice Guidelines (2004) Nephropathy in Diabetes. Diabetes Care, 27, S79-S83.

[4] (2007) KDOQI clinical practice guidelines and clinical practice recommendations for diabetes and chronic kidney disease. American Journal of Kidney Diseases, 49, S12-S154. doi:10.1053/j.ajkd.2006.12.005

[5] Retnakaran, R., Cull, C.A., Thorne, K.I., Adler, A.I., Hol- man, R.R. and UKPDS Study Group (2006) Risk factors for renal dysfunction in type 2 diabetes: UK prospective diabetes study 74. Diabetes, 55, 1832-1839. doi:10.2337/db05-1620

[6] Kramer, H.J., Nguyen, Q.D., Curhan, G. and Hsu, C.Y. (2003) Renal insufficiency in the absence of albuminuria and retinopathy among adults with type 2 diabetes mellitus. JAMA, 289, 3273-3277. doi:10.1001/jama.289.24.3273

[7] MacIsaac, R.J., Panagiotopoulos, S., McNeil, K.J., Smith, T.J., Tsalamandris, C., Hao, H., et al. (2006) Is nonalbuminuric renal insufficiency in type 2 diabetes related to an increase in intrarenal vascular disease? Diabetes Care, 29, 1560-1566. doi:10.2337/dc05-1788

[8] Kramer, C.K., Leitão, C.B., Pinto, L.C., Silveiro, S.P., Gross, J.L. and Canani, L.H. (2007) Clinical and laboratory profile of patients with type 2 diabetes with low glomerular filtration rate and normoalbuminuria. Diabetes Care, 30, 1998-2000. doi:10.2337/dc07-0387

[9] Caramori, M.L., Fioretto, P. and Mauer, M. (2003) Low glomerular filtration rate in normoalbuminuric type 1 diabetic patients: An indicator of more advanced glomerular lesions. Diabetes, 52, 1036-1040. doi:10.2337/diabetes.52.4.1036

[10] Yagil, C., Barak, A., Ben-Dor, D., Rosenmann, E., Bernheim, J., Rosner, M., et al. (2005) Nonproteinuric diabe- 
tes-associated nephropathy in the Cohen rat model of type 2 diabetes. Diabetes, 54, 1487-1496.

doi:10.2337/diabetes.54.5.1487

[11] Tervaert, T.W., Mooyaart, A.L., Amann, K., Cohen, A.H., Cook, H.T., Drachenberg, C.B., et al. (2010) Renal pathology society. Pathologic classification of diabetic nephropathy. Journal of the American Society of Nephrology, 21, 556-563. doi:10.1681/ASN.2010010010

[12] Watanabe, Y., Fujii, H., Aoki, K., Kanazawa, Y. and Miyakawa, T. (2009) A cross-sectional survey of chronic kidney disease and diabetic kidney disease in Japanese type 2 diabetic patients at four urban diabetes clinics. Internal Medicine, 48, 411-414.

[13] Ziyadeh, F.N. and Wolf, G. (2008) Pathogenesis of the podocytopathy and proteinuria in diabetis glomerulopathy. Current Diabetes Reviews, 4, 39-45. doi:10.2174/157339908783502370

[14] Diez-Sampedro, A., Lenz, O. and Fornori, A. (2011) Podocytopathy in diabetes: A metabolic and endocrine disorder. American Journal of Kidney Diseases, 58, 637646. doi:10.1053/j.ajkd.2011.03.035

[15] Najafian, B., Alpers, C.E. and Fogo, A.B. (2011) Pathology of human diabetic nephropathy. Contributions to Nephrology, 170, 36-47. doi:10.1159/000324942

[16] Weil, E.J., Lemley, K.V., Yee, B., Lovato, T., Richardsom, M., Myers, B.D., et al. (2011) Podocyte detachment in type 2 diabetic nephropathy. American Journal of $\mathrm{Ne}$ phrology, 33, 21-24. doi:10.1159/000327047 